Check for updates

London

Cite this as: $B M J 2021 ; 372: n 663$ http://dx.doi.org/10.1136/bmi.n663 Published: 10 March 2021

\title{
Covid-19: NHS Test and Trace made no difference to the pandemic, says report
}

\section{Jacqui Wise}

The NHS Test and Trace service in England failed to deliver its central promise to avoid a second national lockdown and there is no clear evidence its "unimaginable" costs have been justified, MPs on an influential committee have concluded.

The damning report from the House of Commons Public Accounts Committee says that NHS Test and Trace must "wean itself off its persistent reliance on consultants and temporary staff." In early February it was still employing around 2500 consultants at an average daily rate of $€ 1000$ ( $€ 1167 ; \$ 1388)$ with some paid £6624 a day.

Meg Hillier, the committee chair, said, "Despite the unimaginable resources thrown at this project, NHS Test and Trace cannot point to a measurable difference to the progress of the pandemic, and the promise on which this huge expense was justified-avoiding another lockdown-has been broken, twice."

The service, headed by Dido Harding, was set up in May 2020 with a budget of $€ 22 \mathrm{bn}$ and has since been allocated a further £15bn-a total of £37bn over two years.

Hillier said, "For the billions of pounds spent we need to see a top class legacy system. British taxpayers cannot be treated by government like a cash machine. We need to see a clear plan and costs better controlled."

The UK testing capacity for covid-19 increased from around 100 ooo a day in May 2020 to over 800000 tests a day in January 2021. But the report points out that the percentage of total laboratory testing capacity used in November and December 2020 remained under $65 \%$. And, even with the spare capacity, the target to turn around all tests in face-to-face settings in 24 hours was never met.

Mass rapid testing was supposed to be a game changer, but confusion persists over why and how it should be used in different settings, the report says. It points out that several significant commentators, including The BMJ, have raised concerns about the effectiveness of mass testing with lateral flow devices, particularly the high risk of false negatives. It calls for clearer guidance and targets and says any plans should take account of the accuracy and purpose of rapid tests and how to manage the risks associated with false reassurance.

The committee said they welcomed NHS Test and Trace's increasing collaboration with local authorities but questioned why this had not happened earlier. It also was concerned by a lack of engagement with school heads and education stakeholders in the rollout of rapid testing in schools. The report says it should draw on expertise from the wider public health establishment and other sectors including local government, schools, and the hospitality industry.

The report calls on the service to improve the data it publishes so people get a better sense of its effectiveness. Weekly statistics should include the total time taken to reach contacts after a person develops symptoms (the "cough to contact" metric), the number of days people are asked to self-isolate, and compliance with self-isolation.

NHS Test and Trace "still struggles consistently to match supply and demand," resulting in either substandard performance or surplus capacity, the report says. For example, it significantly underestimated the increase in demand for testing when schools and universities returned, resulting in poor performance.

The government must outline its timetable for the service becoming part of the newly formed National Institute for Health Protection, the report says. It also calls for the publication of a strategy in response to the rollout of the vaccination programme and how a degree of readiness can be retained for possible future surges of covid-19.

The committee said it intends to follow progress on NHS Test and Trace later in the year with a second report.

\section{House of Commons Public Accounts Committee. Covid-19: Test, track, and trace (part 1). 10 March 2021. https://committees.parliament.uk/commit- tee/127/public-accounts-committee/publications/reports.}

